05.5

\title{
Намагничивание сверхпроводящих колец импульсами большой длительности
}

\author{
(C) Е.П. Красноперов, В.С. Коротков, А.А. Картамышев
}

НИЦ „Курчатовский институт“, Москва

E-mail: Krasnoperov_EP@nrcki.ru

Поступило в Редакцию 3 апреля 2017 г.

После импульсного намагничивания колец прямоугольного сечения из высокотемпературных сверхпроводников измерена величина захваченного поля в зависимости от времени снижения намагничивающего поля. Показано, что, используя обрыв экранирующего тока, можно однократным импульсом намагничивать кольца до максимальной величины, соответствующей процессу охлаждения в поле (field cooling process).

DOI: 10.21883/PJTF.2017.19.45078.16809

По общему мнению, основанному на экономической целесообразности, наиболее перспективным методом намагничивания монодоменных высокотемпературных сверхпроводников (ВТСП) является импульсное намагничивание. К сожалению, импульсное намагничивание имеет серьезные недостатки: генерируемое изменяющимся полем тепло и невысокая скорость диффузии поля в сверхпроводнике. При низких температурах захваченное поле в дисках оказывается заметно меньше, чем при изотермических условиях, а при высоких температурах, например при $T=77 \mathrm{~K}$, требуемая амплитуда поля в 3 раза превышает захваченное поле [1].

Для получения однородных полей, например, для ЭПР и ЯМР наиболее подходят соленоидальные (трубчатые) конструкции, составленные из шайб [2]. Импульсное намагничивание многосвязных систем, таких как шайбы (кольца), дополнительно осложнено скачками потока, возникающими в результате обрыва экранирующего тока [3]. Обрывы тока возникают в результате формирования высокорезистивного состояния в узком секторе сверхпроводника. Однако этот, казалось бы, негативный эффект может принципиально изменить подход к импульсному намагничиванию многосвязных сверхпроводников. Если длительность 
импульса мала, то магнитное поле уходит из отверстия через еще горячий канал [3, 4]. С другой стороны, благодаря узости канала время его охлаждения существенно короче, чем время остывания всей шайбы (кольца). Если внешнее поле спадает медленнее, чем скорость остывания канала, то за время спада поля критический ток может существенно возрасти. Вопрос состоит в том, как быстро восстанавливается высокая плотность тока и появляется захваченное поле.

В настоящей работе исследуется зависимость величины захваченного поля в отверстии шайбы от длительности спадания намагничивающего поля. Цель исследований состоит в определении условий для максимального намагничивания шайб (колец) однократным импульсом.

Использовалась та же массивная шайба состава $\mathrm{YBa}_{2} \mathrm{Cu}_{3} \mathrm{O}_{7-\delta}$ с внешним и внутренним диаметрами 52 и $25 \mathrm{~mm}$ соответственно и толщиной $10 \mathrm{~mm}$, что в работе [4]. Ось $c$ кристаллитов ориентирована по оси шайбы. Шайба помещалась между парой намагничивающих медных катушек, работающих в апериодическом режиме. Это позволило изменять длительность импульсов с помощью добавочных сопротивлений, включаемых последовательно в цепь катушек. Напряжение на батарее конденсаторов выбиралось таким, чтобы амплитуда поля в катушках была одинаковой для всех импульсов и составляла $\mu_{0} H_{a}=0.6 \mathrm{~T}$. В центре отверстия шайбы устанавливался датчик Холла для измерения магнитного поля. Регистрация экранирующих токов в шайбе осуществлялась калиброванным поясом Роговского. Эксперимент проводился в жидком азоте при $T \approx 77 \mathrm{~K}$.

На рис. 1 изображены экспериментальные зависимости, демонстрирующие обрыв тока при импульсном намагничивании. На рис. $1, b$ показаны осциллограммы внешнего поля (1) и поля в центре шайбы $(2)$, на рис. 1, $a$ - осциллограмма экранирующего тока, циркулирующего в теле шайбы. До момента времени $t \approx 0.02 \mathrm{~s}$ поле в отверстии практически равно нулю, т.е. ток в шайбе полностью экранирует внешнее поле. Затем экранирующий ток достигает максимума, и в отверстие начинает проникать магнитный поток. Далее, как видно из рис. 1, $a$, происходит резкий обрыв тока. В результате магнитное поле скачком проникает в отверстие и практически сравнивается с внешним полем (рис. $1, b)$. В работах [3,4] было показано, что обрыв тока происходит в результате формирования узкой области (канала) высокорезистивного состояния, температура которого на $10-12 \mathrm{~K}$ выше, чем у жидкого азота, в то время как у остальной части сверхпроводника нагрев на

Письма в ЖТФ, 2017, том 43, вып. 19 


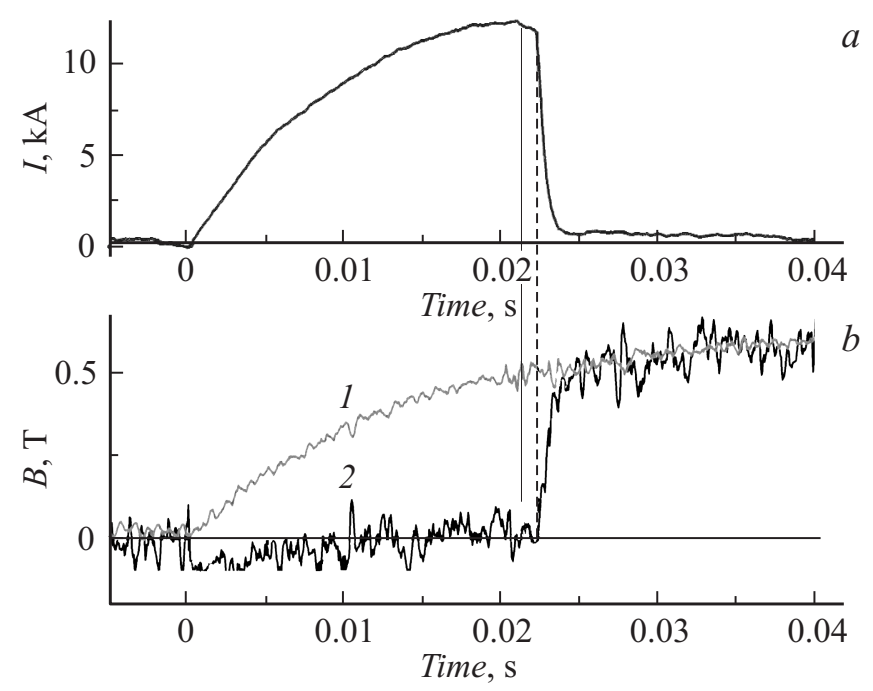

Рис. 1. $a-$ эволюция экранирующего тока на восходящей части импульса, $b$ - эволюция внешнего поля (1) и поля в отверстии шайбы (2).

порядок меньше. Десятикратное падение экранирующего тока на рис. 1 свидетельствует о том, что температура близка к критической $\left(T_{C}\right)$.

При малых длительностях импульса (в данном случае менее $50 \mathrm{~ms}$ ) канал не успевает охладиться, и магнитное поле уходит из отверстия (не захватывается). С увеличением длительности спадающей части импульса в отверстии появляется остаточное (захваченное) поле. На рис. 2 приведены осциллограммы полей для импульса длительностью $400 \mathrm{~ms}$ (время спадания $\tau_{l d} \approx 300 \mathrm{~ms}$ ). В результате обрыва тока и скачка потока поле в отверстии остается равным внешнему до момента времени $t \approx 0.2 \mathrm{~s}$. К этому времени происходит восстановление сверхпроводящего тока настолько, что он способен экранировать внешнее поле. В результате в отверстии захватывается поле $B_{t r} \approx 0.25 \mathrm{~T}$, далее оно слабо изменяется по релаксационному (логарифмическому) закону. Эволюция поля на большом интервале времени показана на вставке к рис. 2.

По обе стороны от осциллограмм схематически изображены распределения полей $B_{z}(r)$ в сверхпроводнике при различных значениях 


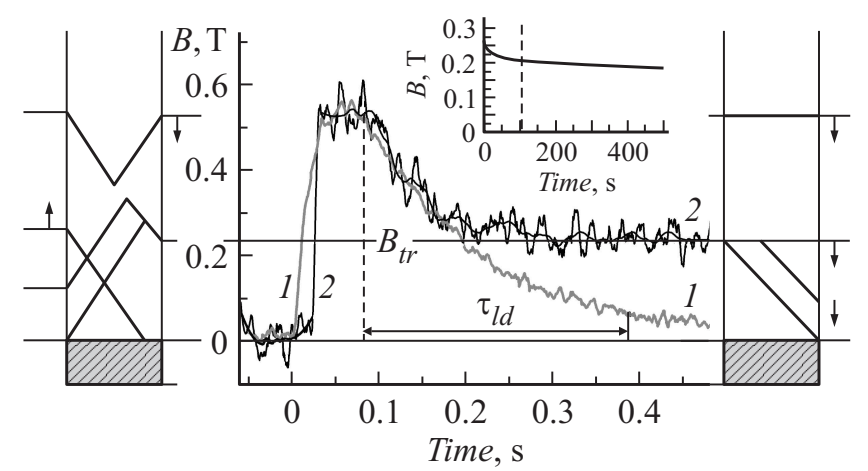

Рис. 2. Эволюция внешнего поля (1) и поля в отверстии (2). Время спада импульса $\tau_{l d} \approx 300 \mathrm{~ms}$. На вставке показана зависимость от времени захваченного в отверстии поля $B(t)$. Слева от рисунка изображено радиальное распределение аксиальной компоненты поля $B_{z}(r)$ в различные моменты времени в теле кольца, справа $-B_{z}(r)$ в канале. Стрелками показаны направления изменения поля.

внешнего поля: слева - поля в теле шайбы $(T \approx 78 \mathrm{~K})$, справа — поля в канале обрыва тока $(T>78 \mathrm{~K})$. Стрелками обозначено направление изменения поля: увеличение $(\uparrow)$ и снижение $(\downarrow)$.

На рис. 3 представлена зависимость захваченного поля от длительности спадания намагничиваюшего импульса $\tau_{l d}\left(\tau_{l d}\right.$ определялось как время от 0.9 максимума импульса до 0.1 его величины, рис. 2). Измерения поля выполнялись через $100 \mathrm{~s}$ после импульса, когда устанавливалось тепловое равновесие. При коротких временах спадания $\left(\tau_{l d}=50-60 \mathrm{~ms}\right)$ температура канала остается высокой, и захваченное поле в центре кольца близко к нулю. ${ }^{1}$ С увеличением длительности спадания, захваченное поле увеличивается и при $\tau_{l d}=300-400 \mathrm{~ms}$ достигает наибольшего значения $B_{t r}=0.22 \mathrm{~T}$.

Быстрое восстановление больших критических токов объясняется высокой теплопроводностью монодоменных ВТСП в плоскости $(a b)$. Характерное время остывания канала можно оценить, пренебрегая отводом тепла от его боковой поверхности в жидкий азот и небольшим нагревом от изменения внешнего поля. Первое оправдано тем,

\footnotetext{
${ }^{1}$ Для коротких импульсов захваченное поле может быть отрицательным [4].
} 




Рис. 3. Зависимость захваченного поля $B_{t r}\left(\tau_{l d}\right)$ от длительности спадания намагничивающего импульса: квадраты - эксперимент, кружки - расчет с учетом охлаждения горячего канала.

что ширина канала существенно меньше его длины $(\sim 3$ и $10 \mathrm{~mm}$ соответственно [4]), а характерное время остывания тела шайбы за счет передачи тепла в жидкий азот составляет десяток секунд [5]. С другой стороны, скорость спадания намагничивающего поля $(d H / d t)$ на порядок ниже, чем $d H / d t$ на восходящей части, соответственно ниже выделение тепла. В нашем случае перегретая область шайбы со средним радиусом $R=2 \mathrm{~cm}$ занимает сектор с углом $\delta \varphi \cong 10^{\circ}[3,4]$. Средний линейный размер перегретой области $w=\delta \varphi 2 \pi R / 360 \cong 0.34 \mathrm{~cm}$. Для решения задачи об остывании удобно рассмотреть стержень с таким же сечением, как у шайбы. Ось стержня расположена в плоскости $(a b)$ монодоменного ВТСП и перпендикулярно оси $c$. У такого стержня с длиной локального перегрева $w$ остывание от температуры, близкой к $T_{C}$, до $78 \mathrm{~K}$ происходит по экспоненциальному закону $\Delta T=\left(T_{C}-78\right) \exp \left(-t_{l} / \tau\right)$, где характерное время остывания составляет $\tau=w^{2} C / 4 k \cong 0.1 \mathrm{~s}$ [6]. Здесь время $t_{l}$ отсчитывается от максимума поля, $C=0.75 \mathrm{~J} /\left(\mathrm{K} \cdot \mathrm{cm}^{3}\right)-$ объемная теплоемкость, $k=0.2 \mathrm{~W} /(\mathrm{cm} \cdot \mathrm{K})$ - теплопроводность в плоскости кристалла $(a b)$ [7].

Письма в ЖТФ, 2017, том 43, вып. 19 
Время остывания $\tau$ оказывается на два порядка меньше, чем время охлаждения шайбы в жидком азоте [5].

Остывание канала приводит к автоматическому росту критического тока. В области от $77 \mathrm{~K}$ до $T_{C}$ критический ток линейно зависит от температуры, поэтому $I_{C}$ со временем возрастает как $I_{C}=I_{77}\left(1-\exp \left(-\tau_{l d} / \tau\right)\right)$, где $\tau=0.1 \mathrm{~s}-$ вычисленное выше характерное время остывания канала. Когда спадающее поле намагничивающего импульса становится равным полю, которое может создать сверхпроводящий ток шайбы, наступает захват поля в отверстии шайбы. Ожидаемые значения $B_{t r}$, полученные таким способом из пересечения зависимостей снижения поля и роста критического тока, показаны на рис. 3 кружками. Отличие расчета от эксперимента, существенное при малых $\tau_{l d}$, по-видимому, связано с неучитываемым разогревом от изменения внешнего поля.

На этой же шайбе было измерено $B_{t r}$ при намагничивании в поле $\mu_{0} H_{a}=0.6 \mathrm{~T}$ с последующим охлаждением сверхпроводника до температуры жидкого азота $(T=77 \mathrm{~K})$ и медленным (изотермическим) выключением поля (FC-процесс). На рис. 3 значение $B_{t r}$ после $\mathrm{FC}$ отмечено штриховой линией. Видно, что процесс $\mathrm{FC}$ и импульсное намагничивание с $\tau_{l d} \geq 300 \mathrm{~ms}$ дают близкие результаты.

Импульсное намагничивание осуществляется после охлаждения сверхпроводника ниже $T_{C}$, т.е. формально является процедурой ZFC (охлаждение в нулевом поле). Однако скачок потока из-за обрыва тока уравнивает внешнее поле и поле в отверстии. Фактически, с этого момента импульсное намагничивание переходит в FC-процесс, и захватываемое поле определяется температурой канала. Близкие значения $B_{t r}$ для обоих процессов свидетельствуют о близости температур в них к $T=78 \mathrm{~K}$. Из данных рис. 2 можно заключить, что времени $t \approx 0.2 \mathrm{~s}\left(\tau_{l d} \approx 0.3 \mathrm{~s}\right)$ достаточно для охлаждения до этой температуры.

Таким образом, при импульсном намагничивании шайб (колец) монодоменных ВТСП происходит обрыв экранирующего тока и формируется высокорезистивный канал, через который магнитное поле скачком проникает в отверстие. В результате импульсное намагничивание из процесса ZFC становится процессом FC. Благодаря малой ширине канала, а также высокой теплопроводности монодоменных ВТСП в плоскости $(a b)$ охлаждение канала и восстановление высоких критических токов происходит достаточно быстро. Это позволяет захватить максимальный магнитный поток однократным импульсом, у которого

3 Письма в ЖТФ, 2017, том 43, вып. 19 
время спадания превышает характерное время теплопередачи. Малый объем канала заметно снижает потери энергии и соответственно нагрев сверхпроводника. Мы полагаем, что импульсное намагничивание с обрывом экранирующего тока может существенно повысить захватываемые поля в монодоменных ВТСП при низких температурах.

\section{Список литературы}

[1] Yanagi Y., Itoh Y., Yoshikawa M., Oka T. // Supercond. Sci. Technol. 2005. V. 18. P. 839-849.

[2] Tomita M., Fukumoto Y., Suzuki K. et al. // J. Appl. Phys. 2011. V. 109. P. 023912.

[3] Korotkov V.S., Krasnoperov E.P., Kartamyshev A.A. // J. Supercond. Nov. Magn. 2016. V. 29. P. 1893-1896.

[4] Korotkov V.S., Krasnoperov E.P., Kartamyshev A.A. The break of shielding current at pulsed field magnetization of a superconducting annulus, Supercond. Sci. Technol., Accepted for publication 30 May 2017.

[5] Korotkov V.S., Krasnoperov E.P., Kartamyshev A.A. // J. Supercond. Nov. Magn. 2015. V. 28. P. 2815-2819.

[6] Carslaw H.S., Jager J.C. Conduction of heat in solids. Oxford, 1959. 510 p.

[7] Ainslie M.D., Fujishiro H., Ujiie T. et al. // Supercond. Sci. Technol. 2014. V. 27. P. 065008. 